\title{
Evaluation the Vickers Hardness of Denture Base Materials
}

\author{
Zeynep Yesil Duymus1, Alper Ozdogan2*, Hamza Ulu², Ozlem Ozbayram² \\ ${ }^{1}$ Department of Prosthodontics, Faculty of Dentistry, Recep Tayyip Erdoğan University, Rize, Turkey \\ ${ }^{2}$ Department of Prosthodontics, Faculty of Dentistry, Atatürk University, Erzurum, Turkey \\ Email: *alprozdgn@gmail.com
}

Received 13 February 2016; accepted 18 April 2016; published 21 April 2016

Copyright @ 2016 by authors and Scientific Research Publishing Inc.

This work is licensed under the Creative Commons Attribution International License (CC BY).

http://creativecommons.org/licenses/by/4.0/

(c) (i) Open Access

\section{Abstract}

The aim of this study was to evaluate the Vickers Hardness of four different denture base materials. Four different denture base materials were used in this study: Heat-cured pink acrylic resin, self-cured acrylic resin, heat-cured clear acrylic resin and polyamide denture base materials. Totally 80 disc shaped samples which $2 \mathrm{~mm}$ thickness and $40 \mathrm{~mm}$ diameter were prepared. The samples were stored in distilled water after polished. Then, Vickers Hardness test was performed with TMTeck HV-1000B (200 gram at 15 second). The statistically analysis of obtained data was performed with use one-way analysis of variance test. The results showed that the highest Vickers Hardness value (18.57 HV) was identified in heat-cured (pink) acrylic resin, the lowest Vickers Hardness value ( $9.62 \mathrm{HV}$ ) was identified in polyamide denture base materials. The result of oneway analysis of variance test showed that there were statistically very highly significant differences between four denture base materials of Vickers Hardness $(p<0.001)$. The obtained data presented that the self-cured denture base acrylic resin was the hardnest denture base materials.

\section{Keywords}

Hardness, Denture Bases, Polyamide

\section{Introduction}

In the clinical practice of dentistry, there are many circumstances in which the need to adjust denture base acrylic resin is necessary [1] [2].

In 1935, first acrylic resin was produced by the imperial kolladent chemical industry.

In 1937, heat-polymerized acrylics which developed by Walter H. Writer, have been used extensively as den-

${ }^{*}$ Corresponding author. 
ture base materials. Acrylic polymers has been successfully used in various areas such as shutters, denture base materials, artificial teeth, denture repair materials, crowns and bridges face the vestibular prosthesis [3] [4].

Denture base polymers are usually supplied as a mixture of poly methyl methacrylate (PMMA) powder beads and methyl methacrylate (MMA) monomer liquid [5]. MMA: Acrylic resin most commonly used in dentistry is metil methacrylate which is the methyl ester of methacrylic acid. The polymethyl methacrylate is formed by the polymerization of styrene. Since 1946, 98\% of all denture base polymers MMA and copolymers began to be performed. Although polymerization could be made ultraviolet and visible light; chemical initiator is commonly used for polymerization in dentistry. During the polymerization of pure methyl methacrylate up to $21 \%$ ratio of a volume shrinkage occurs. PMMA: pure form is a transparent resin. The 0.25 micrometer wavelength UV light can pass even through the acrylic and not be discolored by UV. to create similar colors with tissue, can be used together with many pigment. The advantages of PMMA include excellent esthetic properties, adequate strength, low water sorption, lack of toxicity, facility of repair, and construction by a simple molding and processing technique [6].

The chemically polymerizing acrylics were used for dental purposes first in Germany during World War II. in order to separate from heat polymerized acrylic resin, the "self polymerizing" or "cold polymerized" or "auto polymerized" is called. These are generally used as a repair acrylic, as well can be used as a base acrylic. Compared with heat polymerized resins; the amount of residual monomer and water absorption is higher in the chemically polymerized resins, dimensional stability is less. Since it includes amin accelerators, it is worse compared to polymerization of resins with color harmony. The particle structure is more irregular. Also; the structures weaker and more flexible for the polymer particles have a lower molecular weight [7].

Alternative polymer systems to PMMA, such as polyamide, epoxy, polystyrene, or vinyl acrylic resins, have also been tried. However, the desired denture base material has not been developed yet [8] [9].

A removable partial denture without metal clasps has recently been used in dental practice. In recent years, injection-molded thermoplastic resins such as polycarbonate, polyamide, and polyester have been used as denture-base materials [10] [11]. Injection molded thermoplastic resins (polyamides, polyethylene terephthalate, and polycarbonate) are used for denture bases of RPDs without metal clasps because of their advantageous characteristics, such as a higher elasticity than heat polymerizing base resins, and the fact that they can facilitate denture retention by utilizing the undercuts of abutment teeth in the denture base design [12]. Polyamides, known as "nylon" are thermoplastic polymers produced by condensation between a diamine and a dibasic acid [13].

Firstly, PA was used as a denture base polymer in the studies in $1950 \mathrm{~s}$ [14] and reported that because of the high water absorption and discoloration, the nylon was not suitable materials in dentistry [15].

The aim of this study was to evaluate the Vickers Hardness of four different denture base materials and investigate to the availability of dental prosthesis. The hypothesis this study was that the heat-cured (pink) acrylic resin will has the highest Vickers Hardness value.

\section{Materials and Methods}

Four different denture base materials were used in this study: Heat cured pink acrylic resin QC 20 (De Trey, Dentsply, Addlestone, UK), self-cured acrylic resin Takilon (cold-curing dental polymer, Rodont, Italy), heat cured clear acrylic resin Vertex (Vertex Dental B.V., Zeist, Netherlands) and polyamide denture base materials Deflex (Nuxen S.R.L., Buenos Aires, Argentina) (Figure 1). Totally 80 disc shaped which $2 \mathrm{~mm}$ thickness and $40 \mathrm{~mm}$ diameter were prepared. Firstly wax models were prepared like the size of specimens. They were embedded to dental stone in the stainless steel mold and the mould was created for the acrylic resin. Each acrylic material was mixed according to the manufacturer's instructions and placed to the mould. All specimens were pressed under the 3000 PSI with hydraulic presser. After the acrylic resins were polymerized heat and self. The polyamide dentures were injected with 720 - $750 \mathrm{kPa}$ pressure at $220^{\circ} \mathrm{C}$ and pre-heating time of 15 min according to manufacturer's instructions. After the specimens were prepared, all irregularities were removed with a tungsten carbide bur. The samples were polished and stored in distilled water at $4^{\circ} \mathrm{C}$ until use.

The Vickers Hardness test was performed with TMTeck HV-1000B (TMTeck Manufacturing Limited, Beijing, China) (200 gram at 15 second) to all specimens (Figure 2). The strength was applied to midpoint of base materials by diamond tip. Then, diagonals of trace whose shape is square was measured by microscope and evaluated their values of hardness. The statistically analysis of obtained data were performed with use one-way analysis of variance test by IBM SPSS Statistics 16. 


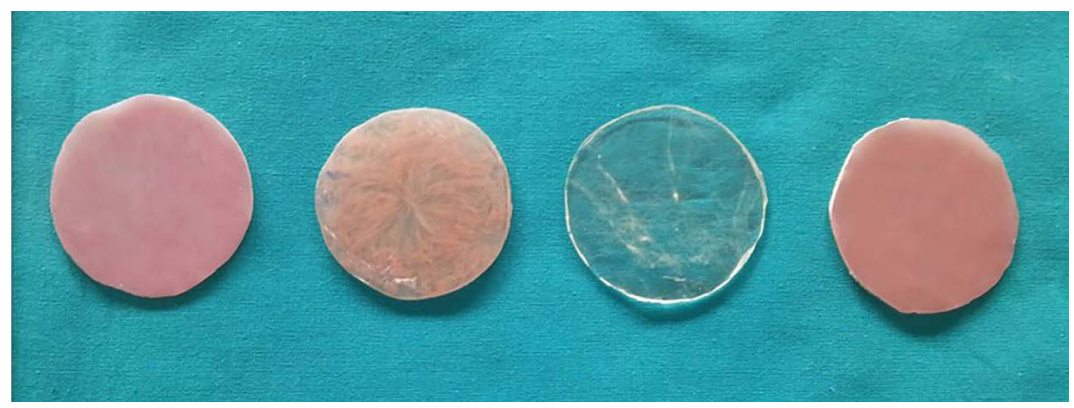

Figure 1. Denture base materials.

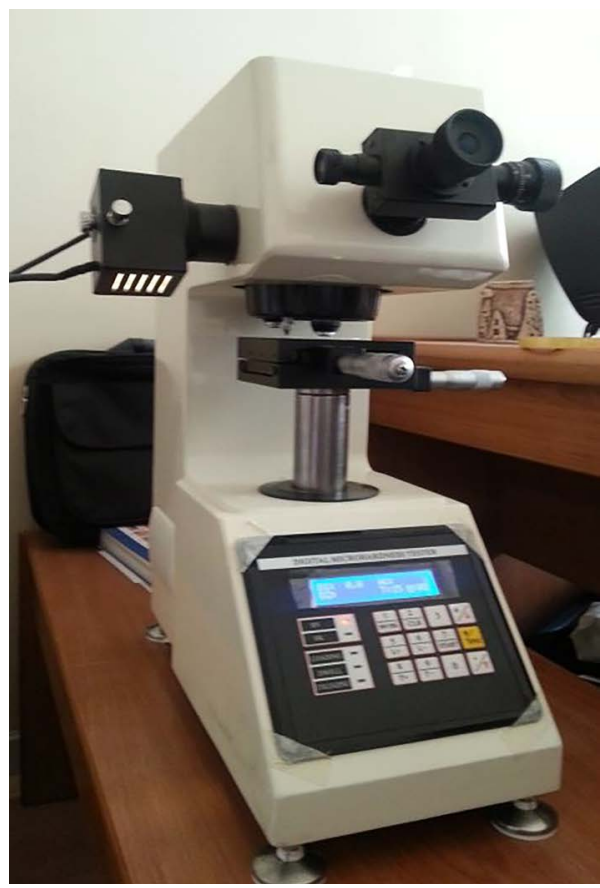

Figure 2. The Vickers Hardness test machine.

\section{Results}

The result of one-way analysis of variance test showed that there were statistically very highly significant differences between four denture base materials of Vickers Hardness $(\mathrm{p}<0.001)$ (Table 1).

The results showed that the highest Vickers Hardness value $(18.57 \mathrm{HV})$ was identified in heat-cured (pink) acrylic resin, the lowest Vickers Hardness value $(9.62 \mathrm{HV})$ was identified in polyamide denture base materials (Table 2, Figure 3).

\section{Discussion}

The hypothesis of this study was accepted, heat-cured (pink) acrylic resin has the highest Vickers Hardness value.

The acrylic resins are usually used in the removable prosthesis for the denture base materials. Acrylics are hard materials so they may disturb the patient during use. Despite the use of soft lining materials, they can cause the canker sores and soft lining materials must be changed over time. The polyamide dentures are used as an alternative for acrylics in removable prosthesis. The polyamide dentures are lighter and have a flexible structure.

Because of the easy specimen preparation, simplicity of the test method and availability of the equipment, hardness has been widely used as a method of investigating factors that influence the degree of conversion of resins and for characterization of the mechanical quality of a polymer [6] [16]-[18]. In this study, Vickers Hardness test was performed to the samples. 
Table 1. The one-way analysis of variance.

\begin{tabular}{cccccc}
\hline & & Sum of Squares & df & Mean Square & F \\
\hline \multirow{2}{*}{ VH } & Between Groups & 862.120 & 3 & 287.373 & 114.074 \\
& Within Groups & 191.459 & 76 & 2.519 \\
& Total & 1053.579 & 79 & & \\
\hline
\end{tabular}

Table 2. Mean HV value of denture base materials $(\mathrm{N}=20)(\mathrm{X}=\mathrm{HV})$.

\begin{tabular}{|c|c|c|c|c|c|c|c|}
\hline & \multirow{2}{*}{ Mean } & \multirow{2}{*}{ Std. Deviation } & \multirow{2}{*}{ Std. Error } & \multicolumn{2}{|c|}{ 95\% Confidence Interval for Mean } & \multirow{2}{*}{ Minimum } & \multirow{2}{*}{ Maximum } \\
\hline & & & & Lower Bound & Upper Bound & & \\
\hline Heat-Cure (Clear) & 16.23 & 1.85202 & 0.41412 & 15.3622 & 17.0958 & 12.32 & 20.11 \\
\hline Heat-Cure (Pink) & 18.57 & 1.35209 & 0.30234 & 17.9372 & 19.2028 & 16.91 & 22.82 \\
\hline Self-Cure & 14.70 & 1.64694 & 0.36827 & 13.9292 & 15.4708 & 10.61 & 16.29 \\
\hline Polyamide & 9.62 & 1.45130 & 0.32452 & 8.9398 & 10.2982 & 8.26 & 13.35 \\
\hline Total & 14.78 & 3.65191 & 0.40830 & 13.9668 & 15.5922 & 8.26 & 22.82 \\
\hline
\end{tabular}

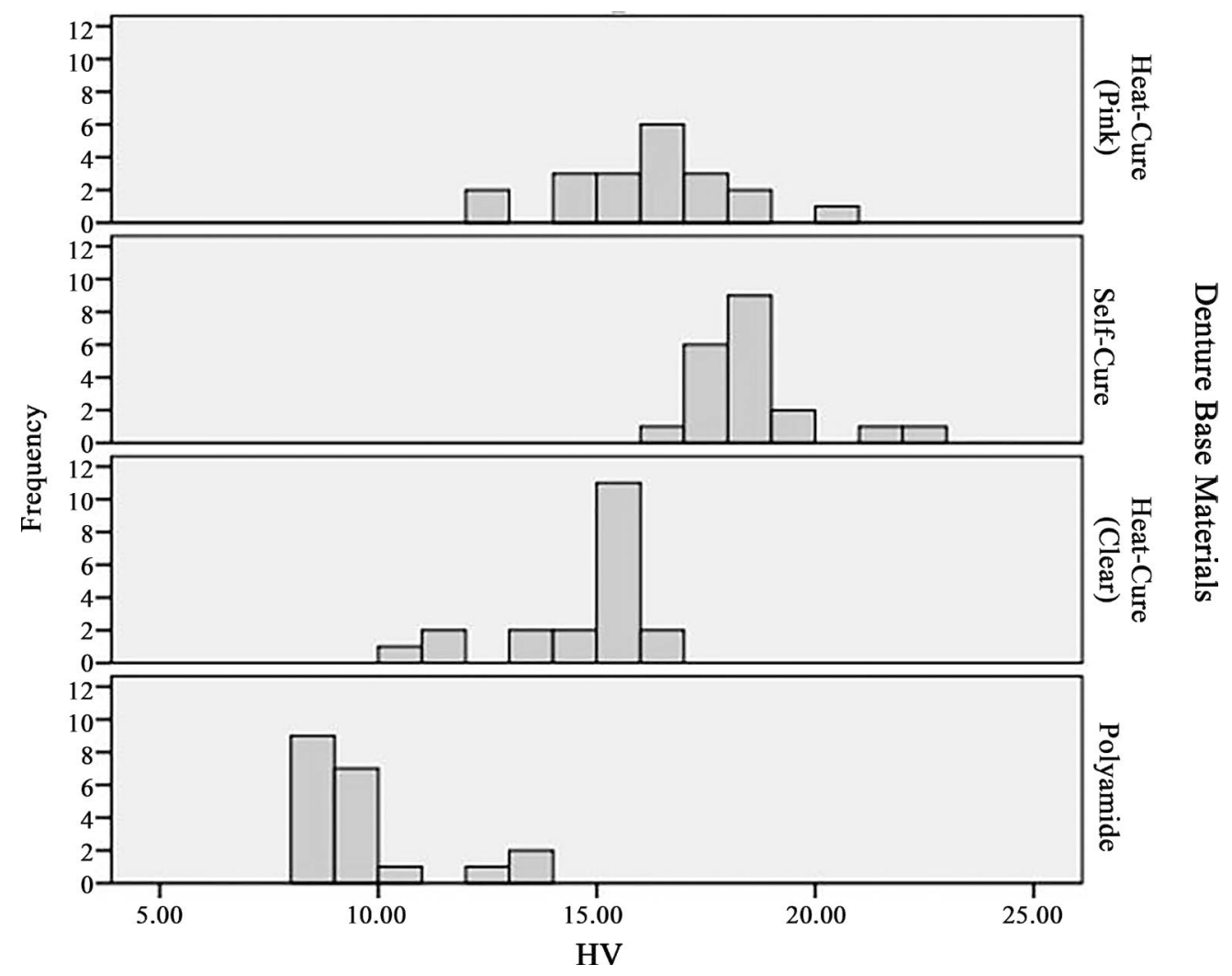

Figure 3. The Vickers Hardness graph of denture base materials.

During the polymerization reaction, the conversion of monomer into polymer is not complete and varying amounts of free or unreacted monomer remain in the polymerized resin [17] [19]-[24]. Residual monomer is a well-known plasticizer and affects the mechanical properties of the acrylic resins [17] [18] [25] [26]. Residual monomers can be polymerized again in the patient's mouth and damage to the patient's mucosa and crest. Considering that self-curing acrylic resins usually exhibit high residual monomer content [17] [23] [24]. For this reason, we usually prefer to heat curing acrylic resins at dental prosthesis. On the other hand, self-curing acrylic resins often use repairing of broken dentures, making the night-guard.

This finding was not to support the other studies, which have shown that the hardness of self-curing acrylic 
resins is lower than that of heat-cured acrylic resins [17] [25] [27]. The values found in this study showed that, the self-curing acrylic resins have higher Vickers Hardness value from heat-curing acrylic resins. The reason of this, acrylic can be turned into a fragile structure at high temperatures. Braun et al. [25] have found that, when submitted to chemical polishing, the heat-cured material was harder than the self-cured one. Another study, Ayaz et al. [28] reported that heat and microwave polymerization techniques did not affect the hardness property significantly.

Heat activates the chemical reaction between the monomer and polymer components of the resin and produces more complete polymerization [29]. This mechanism may explain why hot water conditions improved the mechanical properties of resin.

Pinto et al. [30] reported that polyamide resins had a higher mechanical resistance than acrylic resins. In this study, polyamide had the lowest Vickers Hardness values.

\section{Conclusion}

Within the limitations of this study, it can be concluded that, the head-curing (pink) acrylic resins had the highest Vickers Hardness and polyamide was not as hard as the other materials. The polyamide dentures more should be used in the removable prosthesis to minimize the trauma of prosthesis and the plants of patients.

\section{Acknowledgements}

This study was presented as a poster at $38^{\text {th }}$ Annual Conference of the European Prosthodontic Association \& $21^{\text {st }}$ Scientific Congress of the Turkish Prosthodontic and Implantology Association (EPA 2014) in Istanbul, Turkey, September 2014.

\section{References}

[1] Koran, A. (2002) III: Prosthetic Applications of Polymers. In: Craig, R.G. and Powers, J.M., Eds., Restorative Dental Materials, 11th Edition, Mosby, St. Louis, 635-689.

[2] Rudd, K.D., Morrow, R.M. and Eissmann, H.F. (1981) Flasking, Processing, Deflasking, and Finishing. In: Dental Laboratory Procedures, Vol. 3, Mosby, St. Louis, 394-397.

[3] Mc Cabe, J.F. (1994) Applied Dental Materials. 7th Edition, Mass Publishing Co., London, 200.

[4] Craig, R.G. and Ward, M.L. (1997) Restorative Dental Materials, Mosby Co., St. Louis, 120.

[5] Klemper, D., Sperling, L.H. and Utracki, L.A. (1994) Interpenetrating Polymer Networks. American Chemical Society, Washington DC, 3-11. http://dx.doi.org/10.1021/ba-1994-0239

[6] Craig, R.G. and Powers, J.M. (2002) Restorative Dental Materials. 11th Edition, St. Mosby, Louis, 636-689.

[7] Phillips, R.W. (1991) Skinner's Science of Dental Materials. 11th Edition, W.B. Saunders Co., Philadelphia, 505-53.

[8] Jagger, D.C., Harrison, A. and Jandt, K.D. (1999) The Reinforcement of Dentures. Journal of Oral Rehabilitation, 26, 185-194. http://dx.doi.org/10.1046/j.1365-2842.1999.00375.x

[9] Dogan, O.M., Bolayır, G., Keskin, S., Doğan, A., Bek, B. and Boztuğ, A. (2007) The Effect of Esthetic Fibers on Impact Resistance of a Conventional Heat-Cured Denture Base Resin. Dental Materials Journal, 26, 232-239. http://dx.doi.org/10.4012/dmj.26.232

[10] Goiato, M.C., Panzarini, S.R., Tomiko, C. and Luvizuto, E.R. (2008) Temporary Flexible Immediately Removable Partial Denture: A Case Report. Dentistry Today, 27, 114, 116.

[11] Kaplan, P. (2008) Flexible Removable Partial Dentures: Design and Clasp Concepts. Dentistry Today, 27, $122-123$.

[12] Katsumata, Y., Hojo, S., Hamano, N., Watanabe, T., Yamaguchi, H., Okada, S., et al. (2009) Bonding Strength of Autopolymerizing Resin to Nylon Denture Base Polymer. Dental Materials Journal, 28, 409-418. http://dx.doi.org/10.4012/dmj.28.409

[13] Ucar, Y., Akova, T. and Aysan, I. (2012) Mechanical Properties of Polyamide versus Different PMMA Denture Base Materials. Journal of Prosthodontics, 21, 173-176. http://dx.doi.org/10.1111/j.1532-849X.2011.00804.X

[14] Phoenix, R.D., Mansueto, M.A., Ackerman, N.A. and Jones, R.E. (2004) Evaluation of Mechanical and Thermal Properties of Commonly Used Denture Base Resins. Journal of Prosthodontics, 13, 17-27. http://dx.doi.org/10.1111/j.1532-849X.2004.04002.x

[15] Yunus, N., Rashid, A.A., Azmi, L.L. and Abu-Hassan, M.I. (2005) Some Flexural Properties of a Nylon Denture Base Polymer. Journal of Oral Rehabilitation, 32, 65-71. http://dx.doi.org/10.1111/j.1365-2842.2004.01370.x 
[16] Dunn, W.J. and Bush, A.C. (2002) A Comparison of Polymerization by Light-Emitting Diode and Halogen-Based Light-Curing Units. The Journal of the American Dental Association, 133, 335-341. http://dx.doi.org/10.14219/jada.archive.2002.0173

[17] Lee, S.Y., Lai, Y.L. and Hsu, T.S. (2002) Influence of Polymerization Conditions on Monomer Elution and Microhardness of Autopolymerized Polymethyl Methacrylate Resin. European Journal of Oral Sciences, 110, 179-183. http://dx.doi.org/10.1034/j.1600-0722.2002.11232.x

[18] Rueggeberg, F.A. and Craig, R.G. (1988) Correlation of Parameters Used to Estimate Monomer Conversion in a Light-Cured Composite. Journal of Dental Research, 67, 932-937. http://dx.doi.org/10.1177/00220345880670060801

[19] Dogan, A., Bek, B., Cevik, N.N. and Usanmaz, A. (1995) The Effect of Preparation Conditions of Acrylic Denture Base Materials on the Level of Residual Monomer, Mechanical Properties and Water Absorption. Journal of Dentistry, 23, 313-318. http://dx.doi.org/10.1016/0300-5712(94)00002-W

[20] Harrison, A. and Huggett, R. (1992) Effect of the Curing Cycle on Residual Monomer Levels of Acrylic Resin Denture Base Polymers. Journal of Dentistry, 20, 370-374. http://dx.doi.org/10.1016/0300-5712(92)90031-7

[21] Kedjarune, U., Charoenworaluk, N. and Koontongkaew, S. (1999) Release of Methyl Methacrylate from Heat-Cured and Autopolymerized Resins: Cytotoxicity Testing Related to Residual Monomer. Australian Dental Journal, 44, 25-30. http://dx.doi.org/10.1111/j.1834-7819.1999.tb00532.x

[22] Lamb, D.J., Ellis, B. and Priestley, D. (1983) The Effects of Process Variables on Levels of Residual Monomer in Autopolymerizing Dental Acrylic Resin. Journal of Dentistry, 11, 80-88. http://dx.doi.org/10.1016/0300-5712(83)90051-9

[23] Vallittu, P.K., Miettinen, V. and Alakuijala, P. (1995) Residual Monomer Content and Its Release into Water from Denture Base Materials. Dental Materials, 11, 338-342. http://dx.doi.org/10.1016/0109-5641(95)80031-X

[24] Vallittu, P.K., Ruyter, I.E. and Buykuilmaz, S. (1998) Effect of Polymerization Temperature and Time on the Residual Monomer of Denture Base Polymers. European Journal of Oral Sciences, 106, 588-593. http://dx.doi.org/10.1046/j.0909-8836.1998.eos106109.x

[25] Braun, K.O., Mello, J.A., Rached, R.N. and Del Bel Cury, A.A. (2003) Surface Texture and Some Properties of Acrylic Resins Submitted to Chemical Polishing. Journal of Oral Rehabilitation, 30, 91-98. http://dx.doi.org/10.1046/j.1365-2842.2003.00997.x

[26] Frangou, M.J. and Polyzois, G.L. (1993) Effect of Microwave Polymerization on Indentation Creep, Recovery and Hardness of Acrylic Denture Base Materials. European Journal of Prosthodontics and Restorative Dentistry, 1, 111115.

[27] Von Fraunhofer, J.A. and Suchatlampong, C. (1975) The Surface Characteristics of Denture Base Polymers. Journal of Dentistry, 3, 105-109. http://dx.doi.org/10.1016/0300-5712(75)90060-3

[28] Aydogan Ayaz, E., Durkan, R. and Bagis, B. (2013) The Effect of Acrylamide Incorporation on the Thermal and Physical Properties of Denture Resins. The Journal of Advanced Prosthodontics, 5, 110-117. http://dx.doi.org/10.4047/jap.2013.5.2.110

[29] Gegauff, A.G. and Holloway, J.A. (2001) Provisional Restorations. In: Rosenstiel, S.F., Land, M. and Fujimoto, J., Eds., Contemporary Fixed Prosthodontics, 3rd Edition, CV Mosby, St. Louis, 380-416.

[30] De Rezende Pinto, L., Acosta, E.J., Tavora, F.F., da Silva, P.M. and Porto, V.C. (2010) Effect of Repeated Cycles of Chemical Disinfection on the Roughness and Hardness of Hard Reline Acrylic Resins. Gerodontology, 27, 147-153. http://dx.doi.org/10.1111/j.1741-2358.2009.00282.x 